\title{
Duopoly Competition for Rational Addicts ${ }^{1}$
}

\section{Steven F Koch}

Department of Economics, University of Pretoria

\begin{abstract}
This paper provides an examination of an oligopoly market for addictive commodities, specifically cigarettes. The model is characterized by overlapping generations of consumers and differentiated products. A price equilibrium, which is both stationary and symmetric, is characterized. The model accounts for many of the features within the South African tobacco market. Although excise taxes rose in South Africa, and the actual price in the market rose by more than the increase in the excise tax, the model shows that the increase in the price beyond the excise tax was caused by factors other than the change in the tax rate. The model also points to potential empirical problems associated with estimating cigarette market outcomes, due to the fact that the combination of market structure and addiction may greatly impact the assumed exogeneity of the prices used in the analysis.
\end{abstract}

JEL D42, D92, I12

\section{INTRODUCTION}

Until recently, addiction to a commodity was problematic; it appeared to rely upon irrational behaviour, e.g., it has been publicly stated, for decades, that smoking negatively affects health, yet many individuals continue to smoke and many more have become smokers during the succeeding decades. Becker and Murphy's (1988) seminal paper on rational addiction provided a different view. They showed that rational economic agents might become addicted to a commodity even if that commodity was deleterious to their future health. The intuition behind the paradoxical result is that the benefits of current consumption, which includes the cumulative effects of beneficent experiences, must outweigh the cumulative deleterious effects of past and future consumption. Becker and Murphy provide conditions for which this result holds. $^{2}$

Rational addiction and the empirical examinations of that theory have, for the most part, ignored the potential importance of market organization and market structure, e.g., Becker and Murphy rely upon stable prices in their theoretical 
model to generate the majority of their results. Empirically, Chaloupka (1991), Becker, Grossman, and Murphy (1994), and Grossman, Chaloupka, and Sirtalan (1998) rely on an exogenous price trajectory for their models without specifying the supply side. Below, it is shown that a constant price trajectory assumption is reasonable in those theoretical models because stable prices can be obtained in a more complicated market structure model of rational addiction, as long as the brand loyalty is exogenous to the consumer's decisions. However, the stable price trajectory is endogenous to the model calling into question the validity of their estimations. Importantly, these empirical models instrument past and future prices for past and future consumption, respectively. The instruments used in these empirical examinations, however, are not truly exogenous, and, therefore, their results are likely to be biased.

Rational addiction models have also relied upon single consumer types in their formulations, although it is clear that the demand side can be split into many different types of cigarette consumers. For example, there are young nonsmokers, who may be interested in starting, and there are old addicted smokers, who may be loyal to certain brands. Showalter (1999) examined a theoretical and empirical model of cigarette addiction with monopoly finding that a forward looking monopolist is more important in explaining the data than a forward looking consumer; however, he also relies on one consumer type in his model. This assumption is relaxed below.

Recent work in inter-temporal industrial organization has examined markets in which consumers have switching costs. For an excellent review of this literature, see Klemperer (1995). The switching costs examined by Klemperer (1995), Beggs and Klemperer (1992), Caminal and Matutes (1990), and Padilla (1992) apply to brand loyalty. Specifically, a consumer that has purchased groceries at one store would find it less costly to return to that same store than go to a different store because that consumer would be forced to spend additional time locating items in the new store. Therefore, a switching cost could be associated with experience, e.g., posterior asymmetric learning costs. Furthermore, switching costs can be used to model product differentiation, which is the primary form they take in this paper.

Markets in which consumers have switching costs can be inter-temporally competitive, but not necessarily competitive at any one point in time. For example, two firms would fight for market share initially and be willing to charge a price that is below average cost, because they know that these losses can be recouped in the future as they charge higher prices to consumers who would find it costly to switch to an alternate supplier. Therefore, lifetime profits of the firm are zero because initial profits are negative and future profits are positive. ${ }^{3}$ 
However, lock-in exploitation results often rely upon one customer type, i.e., there is little discussion of how the results would be different if the firms could not discriminate between young, or potential new consumers, and old locked-in consumers. Farrell and Shapiro (1988), in a model that allows for consumer heterogeneity, found that firms face a trade-off between fighting for future market share by charging very low prices and earning rents from the old consumers that have switching costs. Furthermore, they find conditions under which the firms may alternate their prices, i.e., a cyclical pricing scheme where firms charge a low price in one period followed by a high price in the next period; the firms alternately gain market share, and subsequently exploit that market share in the following period.

The model presented here relies, in part, on Klemperer's (1995) proposition that addiction represents a psychological switching cost, perhaps synonymous with withdrawal. However, addiction is not the only switching cost in the model presented here. Besides addiction, there is an additional switching cost associated with brand loyalty. However, it is very likely that addiction will reduce the strength of brand loyalty in the model, since consumers will understand that they are addicted to tobacco, first, and a particular brand of tobacco, second. Although the standard switching cost model would impart brand loyalty on the consumer due to experience, the model presented here considers two separate experiences that are, however, potentially offsetting.

The primary concern addressed in this paper is whether or not addiction affects the major results in inter-temporal industrial organization models. In particular, will duopolies compete differently between and across generations when the commodity they sell is addictive and differentiated in every period? If all consumers were the same, switching costs could enable firms to recoup their investments in addictive capital. ${ }^{4}$ However, different types of consumers will remove some of the investment incentive since consumers cannot be perfectly discriminated against. If, on the other hand, there were no switching costs, it would also be impossible for the firms to invest in addictive capital, since negative profits could not be recouped later. The results in the model provide a justification for the stable price trajectory assumed in rational addiction models, even when the price trajectory is endogenous. Finally, the effect of exogenous factors on the price trajectory is considered.

The remainder of the paper is organized as follows. In Section 2, the economic environment is defined and compared to the situation in South Africa. The behaviour of the firms and the resulting symmetric equilibrium is examined in Section 3. Conclusions, limitations, and possible extensions to the model are presented in Section 4. 


\section{THE ECONOMIC ENVIRONMENT}

The economic environment examined here is concerned with potential smokers. Due to the nature of smoking, these consumers will be from overlapping generations, such that there will be $N^{t}$ young agents (who were born in this time period) and $N^{t-1}$ old agents (who were born in the previous time period) alive during any one epoch. When the consumers are young, they decide whether or not they want to purchase cigarettes. Their decision is determined by current prices, expected future prices, their perception of their own inherent addictive nature, and the degree of product differentiation within the market. Due to the addictive nature of the good, those consumers who buy cigarettes as youths will have a higher willingness to pay for cigarettes when they are older.

The industry is a constant cost industry containing two firms. Each firm is a rational profit maximizing entity, where profits are affected by the degree of lock-in or product differentiation, the degree of addiction, and the tax structure imposed upon them. The Bertrand convention of profit maximization given all other prices is adopted for the analysis, and subsequently, Nash Equilibrium behaviour is examined.

\subsection{Consumers}

Consumers are modelled as two-period lived rational addicts, i.e., utility maximizing potential smokers. Although there are many interesting features incorporated in Becker and Murphy's (1988) paper, the model presented here focuses on the supply side of the market. Therefore, the consumer focus is on the complementary aspect of addiction and utility maximizing rational behaviour. According the Becker and Murphy model, a rational utility maximizing individual can become addicted to cigarette smoking; that premise is the basis for the following general individual demand curves.

$$
\begin{aligned}
& x^{t}=x^{t}\left(p_{t}, q_{t}, E\left[p_{t+1}\right], E\left[q_{t+1}\right] ; \omega^{y}\right) \\
& z^{t}=z^{t}\left(p_{t-1}, q_{t-1}, p_{t}, q_{t} ; \omega^{o}\right)
\end{aligned}
$$

The notation in the paper will continue along these lines; consumption by the newborns will be denoted by $x$, while consumption by the elderly will be denoted with $z$. Prices in the market are denoted by $p$ for one firm and $q$ for the other firm.

Demands for the young consumers are determined by current prices in the market, future prices in the market, and other relevant information; $o$ and $y$ superscripts are used to denote information set knowledge by age group. The 
construction used in the model assumes that changes in the information set only affect the level of demand, and not the elasticity, or more specifically the slope, of demand. It is assumed that young people have only subjective information regarding their own inherent addictive nature, the possibility that cigarettes could adversely affect their health (or employment prospects), the degree to which products are actually differentiated, or the future regulatory environment surrounding the consumption of cigarettes in, for example, public places. In addition, the information set is assumed to include actual and expected future income. Youths cannot be certain of future prices, so their demands must be determined by expectations over those future prices, although perfect foresight will be assumed in the analysis to simplify.

Demands for the aged are determined by past prices in the market, current prices in the market, and other relevant information. The law of demand is assumed to hold true, so that an increase in prices will lead to a decrease in demanded quantities. The complementary nature of addiction means that prices in different time periods will also negatively affect quantities, and, finally, the products from different firms are assumed differentiated, although substitutable. The exact interaction of the price effects within the demand structure, as it relates to firm behaviour is discussed in the Subsection 2.2.

Aggregation of the individual demand curves is assumed possible, and those demands, aggregated to the market level, are explicated below.

$$
\begin{aligned}
& X^{t}=X^{t}\left(p_{t}, q_{t}, E\left[p_{t+1}\right], E\left[q_{t+1}\right] ; \Omega^{y}, N^{t}\right) \\
& Z^{t}=Z^{t}\left(p_{t-1}, q_{t-1}, p_{t}, q_{t} ; \Omega^{o}, N^{t-1}\right)
\end{aligned}
$$

The only differences between individual level demand and market level demand are the number of people in the market and the agglomeration of individual level information; as with information, the change in the number of consumers is modelled to influence only the level of demand and not, at least directly, the elasticity of demand. It is not assumed that every market participant knows every individual's private information. Rather, it is assumed that the important market level information is made available to everyone through the agglomeration. $^{5}$

Although the demands are reasonable approximations of cigarette consumption behaviour, there has been only one analysis, of which I am aware, using this type of demand function in South Africa. The estimates by Van der Merwe and Annett (1998) show that the rational addiction model is reasonable, and that the short-run effect of price changes is smaller than the long-run effect of price changes, although the difference in elasticity is very small, possibly because of 
their modelling of the price-tax relationship. Other analyses of South African cigarette consumers have used the South African Income and Expenditure Survey (SAIES), and, due to limited price data, cannot account for addiction effects. For example, Van Walbeek (2002) shows that fewer poor households than wealthy households, by income quartile, spend money on cigarettes in the 1990 and 1995 SAIES. Ground and Koch (2004) show a similar result using the 2000 SAIES. ${ }^{6}$

\subsection{Firms}

The supply side of the model is assumed to include just two firms denoted by 1 , the target firm, and 2, the target's competition. In 2001, the South African cigarette market was a near monopoly; British American Tobacco (BAT) controlled nearly 90 per cent of the market as measured by sales, while RJ Reynolds (RJR) and Phillip Morris (PM) controlled approximately 10 per cent of the market between them in nearly equivalent shares (Shafey, Dolwick \& Guindon, 2003). For that reason, a pure duopoly is not, necessarily, the correct model of firm behaviour in the South African cigarette market. Rather, a monopoly or collusive oligopoly model might be more reasonable. ${ }^{7}$ However, it is unlikely that BAT can act as a pure monopoly, given the ability of RJR and $\mathrm{PM}$ to import cigarettes from other production sites, even though there remains a 45 per cent import tariff on cigarettes from outside SADC countries (and, either a zero or 36 per cent tariff from within SADC countries, depending on the tobacco content). The important feature of the behavioural model is the fact that neither firm can act as a pure monopolist, either by alone or through collusive efforts. In other words, although the analysed market is South Africa, the primary firms in South Africa are international firms, and, more importantly, there are very few firms producing cigarettes in the world. For that reason, a duopoly model is not unreasonable.

Each firm in the market faces many types of consumers, but is unable to differentiate between them, i.e., it is impossible for a firm to perfectly discriminate. Due to the fact that there are old consumers and young consumers, as well as two different firms, there are three basic types of consumers considering cigarette purchases in any time period, and each basic type of consumer may have different preferences than others within the same category. There are two types of aged consumers, and one newborn type. Of the elderly consumers, some purchased from the same firm, previously, while others purchased from the competing firm, previously. Finally, there are first time consumers, who are currently trying to determine their level of market participation. Not only are there many different types of consumers, the price choices of each firm in period $t$ influences future consumption choices, and, because of past consumer expectations, today's prices also have feedback 
effects on yesterday's consumption choices. The influence of addiction, combined with overlapping generations of consumers, yields this complicated structure. Finally, there are many potential histories leading up to today, due to the continual birth and death cycle in the market.

The Bertrand assumption in the model allows that at time $t$, the target firm chooses its price, $p$, to maximize profits taking all its own past and future prices, as well as all of its opponent's prices, $q$, through time, as given. Due to the infinite nature of the game, the concept of Nash Equilibrium must be modified, and the adopted concept will be a steady-state Nash Equilibrium. ${ }^{8}$

\subsubsection{Elderly consumers}

Each firm may have an installed base of cigarette consumers. For example firm 1 sold brand 1 to a portion, possibly zero, of the youth market. These consumers, who initially purchased brand 1 , return to the market when they are older. By assumption, the fact that they smoked before makes them more likely to want to smoke again. In addition, product differentiation provides an incentive for old consumers, who originally purchased brand 1 , to return to firm 1 to again purchase brand 1 . Although there is an incentive to return, aged consumers will not necessarily return, because they are addicted to tobacco, not just the brand; therefore, firms are limited in their ability to extract relationship rents from the old consumers.

Furthermore, because there are other old consumers in the market with a preference for brand 2 and those individuals have high demand for cigarettes, firm 1 may find it in their interest to pursue elderly consumers who purchased from firm 2 as youths. Therefore, each firm faces two competing interests, in regards to elderly consumers. Those competing interests will be set against each other. Clearly, the degree of lock-in due to brand preference will greatly affect a firm's desire to entice the other firm's consumers to switch brands.

\subsubsection{Youthful consumers}

There are also youthful consumers considering their decision to become smokers. Because addiction increases future demand, firms would like to invest in that future demand, which they might be able to exploit in future, through higher prices. Importantly, however, youth demand is determined by expectations over future prices, i.e., youths are modelled as rational agents who realise the potential for higher future prices. The youths also are expected to realise that firms may compete in the future, depending upon the strength of brand preference, or consumer lock-in. Youths are also influenced by other factors within their information sets. For example, cigarette advertising or other 
promotional behaviours by firms might influence brand choice. Although explicit advertising is illegal in South Africa, and there are other bans on tobacco use, firms can undertake many different activities, e.g., promotion of sports teams or encouraging cigarette smoking in movies.

\subsubsection{Firm profits}

Although the focus within the paper is on the prices of cigarettes, the model does provide enough leeway to consider additional firm strategies, and the effects of those strategies on pricing behaviour. The inclusion of additional strategies would require a simple generalization of the costs of those strategies, as well as assumptions concerning the demand, and, therefore, revenue benefits of the strategies. Below, these costs and benefits will be explicated. Equation (2) defines the general structure of demand, in terms of prices, for the consumers, both old and young; therefore total revenues for any firm will be the multiple of their price and the quantity demanded, which is also determined by other market variables. However, profits today also depend upon profits tomorrow, and in the future. Importantly, future profits are not completely separable from today's decisions, because current prices affect future demand. Combining, profits for firm $i$ from selling brand $i$ can be written as, using the demand curves from equations (2): ${ }^{9}$

$$
\begin{aligned}
& \pi^{1, t}=\left(p_{t}-c_{1}\right) \cdot X^{t}+\left(p_{t}-c_{1}\right) \cdot Z^{t}+\beta \cdot\left(p_{t+1}-c_{1}\right) \cdot Z^{t+1} \\
& \pi^{2, t}=\left(q_{t}-c_{2}\right) \cdot X^{t}+\left(q_{t}-c_{2}\right) \cdot Z^{t}+\beta \cdot\left(q_{t+1}-c_{2}\right) \cdot Z^{t+1}
\end{aligned}
$$

Firms discount future values at the rate of $\beta$, and firm's face constant marginal costs of production, denoted by $c_{i}$.

\section{EQUILIBRIUM BEHAVIOUR}

In this section, the optimising behaviour of the firms is examined. Given the Bertrand assumption, firms are assumed to maximise their respective value functions simultaneously, i.e., without knowing their competitor's price choice. Due to the symmetric nature of the problem, it is convenient and reasonable to examine only one of the firms in the market. Consideration of other factors influencing those strategies will also be discussed.

\subsection{Pricing behaviour}

Each firm is assumed to maximise profits, taking the other firm's behaviour as given. Profits are assumed to be concave, and, therefore, the necessary 
conditions for profit maximisation are enough to characterize firm behaviour. ${ }^{10}$ The necessary condition for firm 1 follows; recall that replacement of $p$ with $q$ and $c_{1}$ with $c_{2}$ will yield the necessary condition for firm 2 . For notation, partial derivatives of functions are denoted as subscripts to the functions; the actual subscript of the function is the variable used for partial differentiation. ${ }^{11}$

$$
\pi_{p_{t}}^{1, t}=X^{t}+\left(p_{t}-c_{1}\right) \cdot X_{p_{t}}^{t}+Z^{t}+\left(p_{t}-c_{1}\right) \cdot Z_{p_{t}}^{t}+\beta \cdot\left(p_{t+1}-c_{1}\right) \cdot X_{p_{t}}^{t}=0
$$

The first two terms on the right hand side represent the marginal profits associated with selling the product only to current youths. The terms only represent the fact that a decrease in price is required to sell more of the product, due to competition from firm 2, as well as the law of demand. The second two terms are marginal profits for selling to the older individuals. Because demand by the elderly, due to addiction, is higher than demand for the youths, the marginal profit for the elderly is assumed to be higher than the marginal profit for the youths, all other things equal. The final term on the right hand side is marginal future profitability. Addiction is synonymous with complementary demand through time, and, therefore, an increase in current prices also reduces future profitability by reducing future demand.

As can be seen in the first order condition, each firm faces multiple trade-offs. If firms were facing only addicted consumers, they would choose high prices, while a firm would choose lower prices if the market contained only youthful consumers. ${ }^{12}$ However, the existence of competition from the other firm limits the possibility to charge higher prices, which further mitigates the possibility for lower prices.

Firm 1 reacts to hypothetical prices by firm 2, based on the first order condition above. Due to the fact that profits are assumed to be concave, the direction of the reaction is determined by the derivative of the optimising condition with respect to firm 2's price. ${ }^{13}$ The derivative of the first order condition is written below, using the same notational devices.

$$
\pi_{p_{t} q_{t}}^{1, t}=X_{q_{t}}^{t}+\left(p_{t}-c_{1}\right) \cdot X_{p_{t} q_{t}}^{t}+Z_{q_{t}}^{t}+\left(p_{t}-c_{1}\right) \cdot Z_{p_{t} q_{t}}^{t}+\beta \cdot\left(p_{t+1}-c_{1}\right) \cdot X_{p_{t} q_{t}}^{t+1}
$$

Because brand 1 and brand 2 are cigarettes, although differentiated, an increase in brand 2's price raises the demand for brand 1; therefore, the first and third terms are positive. The second, fourth, and fifth terms measure, approximately, the change in own-price elasticity resulting from a change in the cross-price. An increase in the cross-price is expected to result in less responsive demand; the higher cross-price reduces the substitutability between the two products. Recalling that the slope of demand is negative, a reduction in responsiveness 
means a less negative slope, or an increase in the slope. Therefore, all five terms are positive, and the reaction function is upward sloping, just as expected in a heterogeneous goods Bertrand oligopoly.

The symmetric nature of the two firms means that there will exist a symmetric steady-state Nash Equilibrium. That result is stated, without proof in Theorem $1^{14}$, and a representation of the equilibrium is illustrated in Figure 1.

\section{Figure 1 An illustration of the stationary equilibrium}

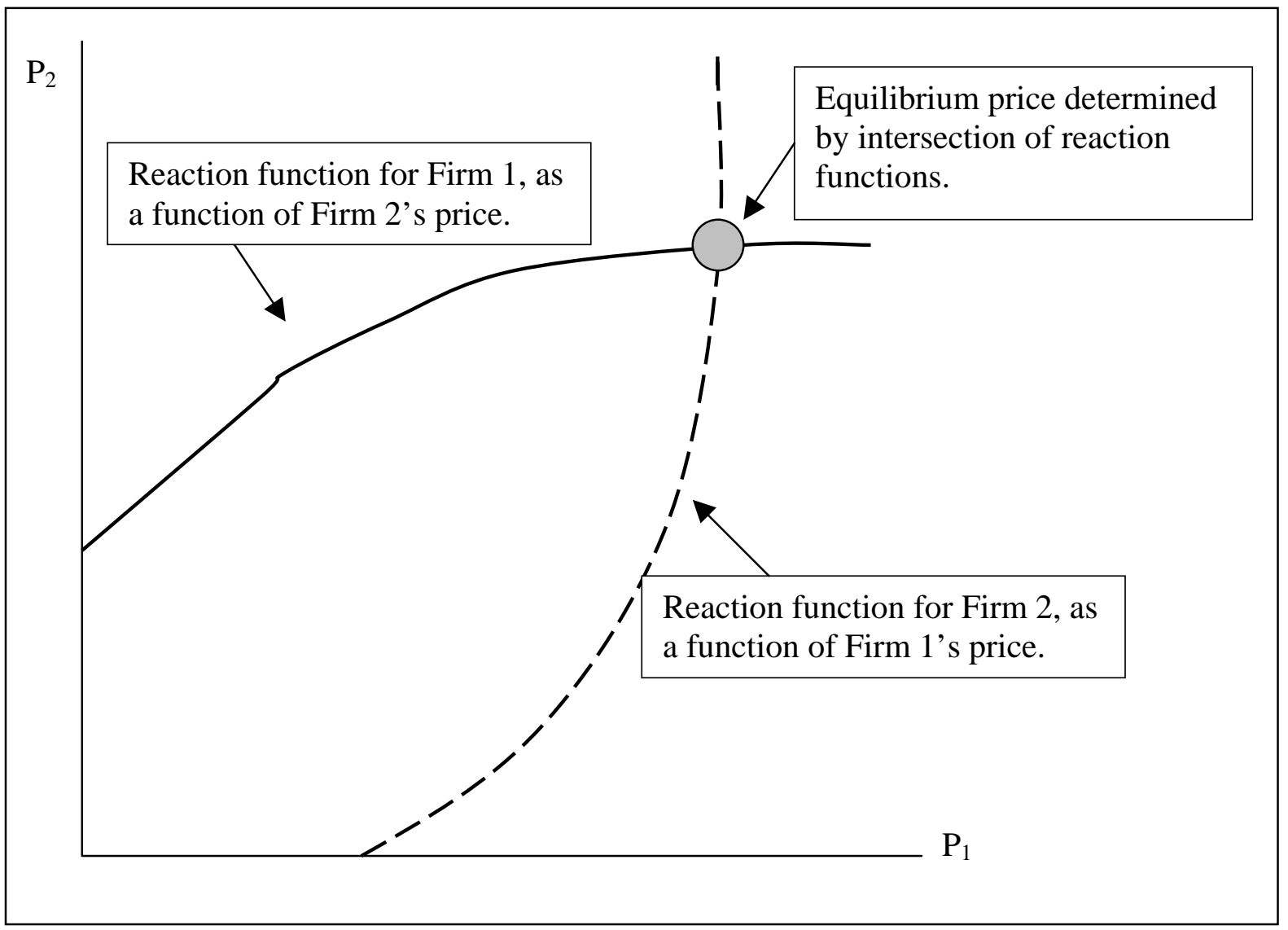

Theorem 1: There exists a steady-state Nash Equilibrium to this Bertrand pricing game.

\subsection{Properties of the equilibrium price}

From the demand functions, as well as the profit functions, it can be seen that there are a number of exogenous factors that can affect the equilibrium price in the market. For example, government policies that raise the opportunity cost of smoking, through taxes or indoor clean air laws, will affect demand; new information concerning the health affects of smoking will affect demand; government policies affecting advertising behaviour will affect demand; the 
addictiveness of the cigarettes, or smoking in general, is also likely to affect demand.

In a model of this nature, the equilibrium price will change as a result of a change in the reaction function. Changes in the reaction function are determined in the same way as the actual slope of the reaction function, by the application of simple comparative statics. Theorem 2 provides a summary of those comparisons.

Theorem 2: The equilibrium price in the market increases with increases in: the number of consumers (old or young) in the market and with increases in the costs of production (including taxes); however, the rate of increase in prices will be less than the increase in the tax. The equilibrium price in the market decreases in the relative importance placed on the future, announcements of deleterious health consequences, and the enactment of clean indoor air laws.

Proof: See Appendix A for the mathematical derivation.

Intuitively, any factor that decreases demand will lower the price, while any factor that raises costs to the firm will raise the price. Fewer smokers, for whatever reason, lowers demand, while an increase in taxes will raise costs to the firm. Moreover, the fact that prices cannot rise faster than costs is due to the fact that the reaction functions are upward sloping. In the limit of horizontal reaction functions, the prices would increase the exact same amount as the increase in the excise rate.

The effect of an advertising ban is, however, contentious. Although such a ban would lower demand, suggesting a decrease in price, that same ban on advertising would raise the costs of brand promotion, on the assumption that advertising is a more cost effective way of meeting customers than any other activity. ${ }^{15}$ Therefore, the outcome cannot be determined $a$ priori. A similar result is true for the degree of addictiveness, for a slightly different reason. Although addiction increases future demand, and thus leads to a desire for higher prices, the degree of addictiveness leads firms to want to charge lower prices for young consumers, to get them to buy more in the future. In addition, rational youth may be less inclined to participate in the market if they are afraid of becoming addicted to cigarettes.

\subsection{Relating to South Africa}

According to Van der Merwe and Annett (1998), the real gap between the final price of cigarettes and the cigarette excise tax in South Africa was roughly constant between 1970 and 1988, at approximately 6 cents per cigarette. 
Although the gap began to widen around 1988, following 1993, the gap widened significantly, leading Van Walbeek (2000b, 2002) to suggest that firms were passing through to the consumers more than just the excise taxes, due to a decrease in sales volumes. The model presented here predicts the result, although the result is not an increase in excise tax pass-through. Rather the result is that youth interest in cigarette consumption fell significantly, forcing firms to focus more on their already addicted consumers.

Further proof obtains from the relationship between cigarette sales and population growth. Between 1970 and 1993, the real price of cigarettes fell significantly, nearly 40 per cent. During the rest of the 1990s, on the other hand, the real price of cigarettes doubled, partially due to a 225 per cent increase in real excise taxes (Van Walbeek, 2002); real excise taxes were lowest, at 56 cents per pack, in 1991, and rose to 164 cents per pack by 1999 (Van Walbeek, 2000a). Similarly, consumption peaked in 1991, and fell precipitously by the end of the decade. According to Shafey, Dolwick, and Guindon (2003), per capita cigarette consumption per year fell from 1665 cigarettes in 1990 to 933 cigarettes in 2000, a reduction of 44 per cent; however, total consumption of cigarettes fell from 37.4 billion to 26.7 billion over the same time period, a reduction of only 28.6 per cent. Back of the envelope calculations put the elasticity of cigarette demand at 0.22 per capita and 0.14 per cigarette. $^{16}$ Clearly, population growth is overstating the responsiveness of consumers to the price changes. More realistically, fewer young consumers are purchasing cigarettes, but there has been very little change in behaviour for the elderly addicts.

Further consideration of the growth in the price gap, the difference between the excise tax value and the final sale price, since 1988, agrees with the model presented here, as well. A reduction in the number of young consumers changes the relative weighting within any firm's reaction function towards pricing for the elderly addicted consumers. Such a change in the number of young consumers would have resulted from the spread of information regarding the adverse health consequences of smoking. The fact that the gap began to widen, in 1988, before the real excise tax rate increased in 1992, implies that there were factors in the marketplace, other than taxes, leading firms to rethink their pricing strategies. The increase in the price gap, in 1988, was due to the adverse change in youthful demand factors, not the increase in excise taxes. However, the increase afterwards included both the excise tax effect and the decrease in youth consumption.

Other authors have suggested that firms might have coordinated on price increases based on increases in the tax rates; Harris (1987) has made this suggestion in the case of the US. Barnett, Keeler, and Hu (1995) and Sung, Hu, 
and Keeler (1994) provide empirical support using US data. Using South African data, Van der Merwe and Annett (1998) also show that prices rise faster than the rate of increase of the excise taxes. However, none of these empirical models attempt to capture a change in the consumption profile in the market, especially the age-consumption profile. For that reason, the hypothesis and empirical support of the hypothesis that taxes will, alone, lead firms to raise prices by more than the tax rate is unconvincing.

\section{CONCLUSIONS AND EXTENSIONS}

In this paper, a model of a market with brand loyalty, addiction and price competition has been presented. The model is representative of the South African situation in terms of structure, and, most importantly, in terms of findings. The primary result presented in the paper is that an oligopoly market over addictive and differentiated products can result in stable prices in equilibrium, thus validating the assumption used in a number of the theoretical and empirical models of rational addiction. In addition, the factors affecting the stationary equilibrium were discussed. The effect of those factors is, importantly, intuitive, despite the complexity of the model.

Firms in the market face trade-offs when they choose their prices. They would like to discriminate by age, or, more accurately, by experience. Before the introduction of bans on firm give-aways of tobacco samples, firms could attempt to expand their markets by promotional activities attended by young people, who were not likely to be, as yet, smokers. The introduction of these bans, has eliminated an outlet for discriminatory pricing. On its own, the elimination of price discrimination should have reduced the market price of cigarettes; however, the increase in the excise taxes as well as the spread of information regarding the adverse health consequences of cigarette smoking, has overridden the expected effect of the promotional ban. Most importantly, prices have risen faster than the rate of excise taxes. The result does not obtain because firms are colluding on price behaviour or because the market is monopolistic, but because the reduction in youth demand has led firms to focus more on the profitable, already addicted, smokers.

The model shows that prices in the market do not follow an exogenous trajectory, because behaviour at one time depends on past behaviour as well as expected future behaviour. Therefore, careful consideration must be taken when empirically estimating the demand for cigarettes, i.e. appropriate instruments need to be used, because demand cannot be estimated separate from supply. The logical choice, excise taxes, which are set by government and likely to be exogenous, may not be purely exogenous, since other demand 
factors determine the degree of pass-through of the excise taxes into the final sale price.

The model is limited, in that it is only a duopoly model, although the nature of the South African situation makes this reasonable. Furthermore, the exact nature of the branding decisions is not considered. Firms in this model have an incentive to create new brands in every time period and sell them well below cost. This degree of differentiation would allow for price discrimination across time, which could lead to an increase in profits, if it were not too expensive to engage in brand proliferation.

Finally, the heart of the rational addiction model is that consumers choose to smoke of their own cognisance, and rationally understand they may die at an early age. For that reason, there is no reason to regulate cigarette sales in this model; excise taxes are welfare decreasing in the model. ${ }^{17}$ Therefore, the model must be extended to allow for true externalities, e.g. the use of chemicals to enhance nicotine absorption in unknowing consumers. Although the general framework presented here would allow for such an examination, the analysis presented here was only concerned with pricing behaviour, and therefore, was not able to address those considerations.

\section{ENDNOTES}

1 This research is based on a simplified version of Koch (1997); the paper has been greatly modified over the years into its present form. The author would like to thank Derek Laing, Michael Baye, Paul Jensen, Brad Kamp and three anonymous reviewers for their comments on this paper. All normal disclaimers apply.

2 Koch (2001) shows that the Becker and Murphy conditions are synonymous - although less able to generate all the features of Becker and Murphy - with an assumption of increasing marginal utility associated with smoking through time.

3 The results of consumer switching cost models depend upon the market assumptions. For example, in an infant market, firms compete for market share in early periods, which allows them to extract monopoly profits in the succeeding periods. The industry might then appear to be imperfect, when in fact, the future monopoly profits are exactly offset by marketshare competition losses resulting in perfectly competitive lifetime profits.

4 Firms could choose a low price for consumers now to garner larger future demands. They could make up for these losses by charging a higher price tomorrow on the larger demand. The firm may not actually make losses; 
however, they will clearly lose compared to what they would make if they chose the price, while ignoring the future.

5 Due to the different results that could arise in markets with private or asymmetric information, it might be interesting to consider the effects of such an analysis. However, the model here assumes that all consumers are atomistic, and, therefore, transactions are of the posted-price variety, where consumer's take-it-or-leave-it. In that setting, although private information may upset the overall efficiency of the market, modelling it is unlikely to add any insight to the model, without adding unnecessary complexity to the analysis.

6 Given the large number of brands of cigarettes, it is possible individuals of differing levels of wealth have different preferences for cigarettes or that cigarette manufacturers specifically market cigarettes to people of different categories of income. The model presented here does not examine that question specifically. Future research into branding behaviour and marketing would greatly improve the understanding of the cigarette market.

$7 \quad$ I thank a reviewer for pointing out this concern.

8 Nash Equilibrium is a set of strategies that result in optimum payoffs for both firms, provided their competing firm is optimising profits as well. Importantly, in an infinite game, without beginning or end, a set of strategies is difficult to characterize or examine. For that reason, a steady-state Nash Equilibrium concept is considered here.

9 In reality, profits are an infinite sum over the periods of the game. Therefore, equation (3) only represents the value function, or the part of profits, dependent upon the current price choice.

10 An assumption of linear demand curves and future price effects that did not outweigh current price effects would be enough to guarantee concavity. The bigger concern is differentiability. In the standard Bertrand game of homogeneous products, the profit function is not differentiable, due to large jumps in profits associated with small changes in prices. In this model, products are assumed differentiated, which will keep the profit function differentiable.

11 Only profits, $\pi$, youth demand, $X$, and elderly demand, $Z$, are functions of either firm's prices or other market variables.

12 It may be possible for a cyclical steady-state equilibrium to exist, where firms take turns charging high prices in one period and low prices in another period. However, such a pricing strategy has never existed in practice, and, therefore, the possibility will not be examined. Furthermore, the assumption of differentiable profit functions makes the cyclical result unlikely, due to the lack of lumpiness in profitability; see, for example, Koch (1997). 
13 This result is merely an extension of the application of comparative statics. See Appendix A for a more detailed description.

14 A proof is available from the author upon request. Intuitively, symmetry of the equilibrium is guaranteed by the symmetry of the problem, while Nash Equilibrium is nearly guaranteed by the fact that each firm can maximise their respective profits. The final piece requires proving that an intersection of the reaction functions exist, which is accomplished by showing, for example, that there exists a firm 1 reaction that is below firm 2's price, given some price for firm 2, and that there also exists a firm 1 reaction that is above firm 2's price, given some other price for firm 2.

15 The ban on promotional give-aways, however, is less contentious. The fact that firms can no longer follow a useful price discrimination strategy (giving away the product at places, like dance clubs, attended by youths, while otherwise selling the product for a positive price) that might lead to increased future demand, they are left with no choice other than to lower the price of cigarettes to try to entice new consumption.

16 The calculations are based on a 200 per cent increase in the real price as reported in Van Walbeek (2002).

17 Increased excise taxes reduce consumption quantities and profits, thus negatively affecting consumers and firms. The long-term effect is also negative, because, in the rational addiction model, consumers were assumed to choose positive consumption quantities taking into consideration the long-term negative effects of cigarette smoking.

18 The number of consumers that participate in the market is assumed to be exogenously determined in the market, while prices are assumed to influence that actual level of consumption of those consumers. 


\section{APPENDIX A}

\section{A. Proof of Theorem 2}

Consider the first order condition from the text, which is, in its most basic form, $\pi_{p_{t}}^{1, t}=0$. Taking the total differential of the necessary condition with respect to own price and some other variable that also influences the necessary condition, while maintaining the assumption of optimality, results in: $\pi_{p_{t} p_{t}}^{1, t} d p_{t}+\pi_{p_{t} \theta}^{1, t} d \theta=0$. Recall from the text, if $\theta=q_{t}$, the price charged by firm 2, then $\pi_{p_{t} \theta}^{1, t} d \theta>0$, due to the substitutability of the products. More formally, with the exception of a change in $c$ or $\beta$,

$\pi_{p_{t} \theta}^{1, t}=X_{\theta}^{t}+\left(p_{t}-c_{1}\right) \cdot X_{p_{t} \theta}^{t}+Z_{\theta}^{t}+\left(p_{t}-c_{1}\right) \cdot Z_{p_{t} \theta}^{t}+\beta \cdot\left(p_{t+1}-c_{1}\right) \cdot X_{p_{t} \theta}^{t+1}$.

Given an increase in the number of consumers in the market, which could be a result of a government information campaign or other regulation, but not because of a change in prices (by assumption), ${ }^{18}$ condition A.1 becomes $\pi_{p_{t} N^{t}}^{1, t}=X_{N^{t}}^{t}>0$. A change in the number of elderly consumers yields $\pi_{p_{t} N^{t-1}}^{1, t}=Z_{N^{t-1}}^{t}>0$.

In the case of a change in $c$, equation (A.1) becomes $\pi_{p_{t} c_{1}}^{1, t}=-X_{p_{t}}^{t}-Z_{p_{t}}^{t}-\beta X_{p_{t}}^{t}>0$, due to the law of demand (the first term) and the complementary nature of demand (the second term). While, in the case of a change in $\beta$, equation (A.1) becomes $\pi_{p_{t} \beta}^{1, t}=\left(p_{t+1}-c_{1}\right) \cdot X_{p_{t}}^{t+1}<0$. The result is also due to the complementary nature of demand. Because each of these changes happens to each firm's reaction function similarly, and, therefore, the change in market prices will be symmetric, as was the equilibrium, unless a change only affects one of the firms in the market. 


\section{REFERENCES}

1 BARNETT, P.G., KEELER, T.E., \& HU, T. (1995) "Oligopoly structure and the incidence of cigarette excise taxes", Journal of Public Economics 57(3): 457-70.

2 BECKER, G.S.M. \& MURPHY, K. (1994) "An empirical analysis of cigarette addiction”, American Economic Review 84(3): 396-418.

3 BECKER, G.S. \& MURPHY, K. (1988) “A theory of rational addiction”, Journal of Political Economy, 96: 675-700.

4 BEGGS, A.W. \& KLEMPERER, P.D. (1992) "Multi-period competition with switching costs", Econometrica 60 (3): 651-66.

5 CAMINAL, R. \& MATUTES, C. (1990) "Endogenous switching costs in a duopoly model”, International Journal of Industrial Organization 8(3): 353-73.

6 Chaloupka, F. (1991) "Rational addictive behaviour and cigarette smoking”, Journal of Political Economy, 99(4): 722-42.

7 FARRELL, J. \& SHAPIRO, C. (1988) "Dynamic competition with switching costs." Rand Journal of Economics 19(1): 123-37.

8 GROSSMAN, M., CHALOUPKA, F. \& SIRTALAN, I. (1998) “An empirical analysis of alcohol addiction”, Economic Inquiry, 36(1): 39-48.

9 GROUND, M, \& KOCH, S.F. (2004) "Alcohol demand in South Africa: A systems approach”, Unpublished University of Pretoria Manuscript.

10 HARRIS, J.E. (1987) "The 1983 increase in the federal cigarette excise tax,” in Summers, L. (ed.) Tax Policy and the Economy, vol. 1, NBER and MIT Press Journals: 87-111.

11 KLEMPERER, P.D. (1995) "Competition when consumers have switching costs”, Review of Economic Studies 62(4): 514-540.

12 KOCH, S.F. (1997) "Essays on intertemporal complementarity and market structure", The Pennsylvania State University Ph.D. Thesis.

13 PADILLA, J.A. (1992) "Mixed pricing oligopoly with consumer switching”, Industrial Journal of Industrial Organization 10(3): 393-411.

14 ROBERTS, M. J. \& SAMUELSON, L. (1988), “An empirical analysis of dynamic, non price competition in an oligopolistic industry." Rand Journal of Economics 19: 200-20.

15 SHAFEY, O., DOLWICK, S. \& GUINDON, G.E. (2003) “Tobacco control country profiles”, UICC Globalink. http://www.globalink. org/tccp/.

16 SHOWALTER, M.H. (1999) "Firm behaviour in a market with addiction: The case of cigarettes", Journal of Health Economics, 18(4): 409-27.

17 SUNG, H., HU, T. \& KEELER, T.E. (1994) "Cigarette taxation and demand: An empirical model.” Contemporary Economic Policy, 12(3): 91-100. 
18 VAN DER MERWE, R. \& ANNETT, N. (1998) "The effects of taxation on consumption in South Africa," Chapter 4 in The Economics of Tobacco Control in South Africa, Report submitted to the International Tobacco Initiative, School of Economics, University of Cape Town.

19 VAN WALBEEK, C.P. (2000a) "Impact of the recent tobacco excise tax increases in South Africa”, Economics of Tobacco Control Project, University of Cape Town, Research Release no. 1.

20 VAN WALBEEK, C.P. (2000b) "Industry responses to the recent tobacco excise tax increases in South Africa”, Economics of Tobacco Control Project, University of Cape Town, Research Release no. 2.

21 VAN WALBEEK, C.P. (2002) "The distributional impact of tobacco excise increases”, South African Journal of Economics, 70(3): 560-78. 